\title{
Inference of Word Meaning in Accordance with Definition Presentation and Context Presentation for Children with Borderline Intellectual Functioning
}

\author{
Eunji Kim ${ }^{\mathrm{a}}$, Mina Hwang ${ }^{\mathrm{b}}$, Sunhee Ko ${ }^{\mathrm{a}}$ \\ 'Department of Speech Language Pathology, Graduate School, Dankook University, Yongin, Korea \\ ${ }^{b}$ Department of Special Education, Dankook University, Yongin, Korea
}

Correspondence: Sunhee Ko, PhD Department of Speech Language Pathology, Graduate School, Dankook University, 152 Jukjeon-ro, Suji-gu, Yongin 16890, Korea Tel: $+1-224-723-4528$

Fax: $+1-847-941-8830$

E-mail: sun7610@hanmail.com

Received: April 1, 2016

Revised: May 10, 2016

Accepted: May 20, 2016

\begin{abstract}
Objectives: This research studied if children with borderline intellectual functioning (BIF) showed a difference in performance compared to normal children when processing word meanings with a presented definition and a presented context. Methods: The subjects included 10 children with BIF and 10 normal children. The children were asked to choose one sentence among 3 options which included a nonword used the same meaning with the target sentence after reading target sentences with nonwords. Subsequently, the target sentences were divided into two conditions: presenting the definition directly and presenting a context from which the nonword's meaning could be inferred. Results: Children with BIF performed significantly lower than normal children when they processed nonword meanings. And while normal children performed evenly regardless of conditions, children with BIF showed significantly poorer performance when presented with a context for meaning rather than a definition. In addition, when analyzing types of errors children with BIF chose the sentence unrelated to the meaning of the nonword used in the target sentence more often than normal children. Conclusion: Children with BIF struggle with acquiring the meaning of new words, especially when it is necessary to infer that meaning through context. They require intervention to improve this skill.
\end{abstract}

Keywords: Borderline intellectual functioning, Inference of word meaning, Context
정신장애 진단 및 통계편람 DSM-IV (Diagnostic and Statistical Manual of Mental Disorders, fourth edition; American Psychiatric Association, 2000)에 의하면 경계선 지능이란 지능 지수가 70 이상 85 미만인 경우를 말하며, 전체 인구의 $12 \%$ 가 이에 해당된다 (Dunham, Schrader, \& Dunham, 2000). 특히, 경계선급 지능 아동 들의 경우 드물지 않게 일반 학급에 배치되어 있으나 이들은 지적 장애나 단순언어장애의 진단 기준에 부합되지 않기 때문에 부모나 교사들 역시 이들의 문제를 인지하지 못하는 경우가 많고, 이로 인 해 적절한 진단 및 중재에서도 배제되기 쉽다. 그러나 경계선급 지 능 아동들이 고학년으로 올라갈수록 일반 아동들에 비해 고차원 적인 언어 습득에 어려움을 보이며, 읽기 및 쓰기의 저조한 수행 때 문에 학습 부진으로 분류되기도 한다(Lim \& Hwang, 2006).

일반적으로 경계선급 지능 아동들은 생의 초기에 일반 아동들
과 유사한 발달을 보이며, 기본적인 의사소통에 있어 크게 어려움 을 보이지 않는 것으로 보고된다(Jung \& Lee, 2005; Yu, Jeong, \& $\mathrm{Kim}, 2007)$ 하지만 이들은 연령이 증가함에 따라, 점차적으로 추 상적인 개념을 이해하고 습득하는 데 지체를 보이고(Singh, 2004), 상위 인지 능력의 결함으로 추론이나 논리적인 사고를 통해 새로운 개념을 이해하고 적용하는 데 일반 아동에 비해 많은 시간과 노력 이 필요하며, 일반화를 이끌어 내기 위해 이전에 배운 정보와 새로 운 정보를 통합하는 데도 어려움을 보이게 된다(Cooter \& Cooter, 2004; Jensen, 1998; Verguts \& De Boeck, 2001).

이 같은 이들의 인지 및 언어적인 특성을 고려한다면, 경계선급 지능 아동들이 새로운 어휘를 습득하는 데도 저조함을 보일 것으 로 예측할 수 있다. 어휘는 개인의 인지 능력을 구성하는 핵심 요소 이며(Lee, 1997), 학령기 아동의 읽기 이해 능력 및 학업 성취를 가 
장 잘 예측해주는 요인 중 하나이다(Kurdek \& Sinclair, 2001; Kim \& Hwang, 2008; Kim, Yoo, Hwang, Kim, \& Koh, 2010). 학령전기 아동들은 구어를 기반으로 하여 어휘를 확장해 나가는 반면, 학령 기 아동들은 다양한 읽기 경험을 통해 광범위한 어휘들에 노출되 면서 기하급수적으로 어휘를 확장해 나가는 특징이 있다(Cain, Oakhill, \& Lemmon, 2004; Cunningham \& Stanovich, 1998; Nagy, Herman, \& Anderson, 1985; Nagy \& Herman, 1987; Sternberg, 1987). 이렇듯 어휘력이 학령기 아동들의 학습에서 중요한 역할을 하지만 학령기 경계선급 지능 아동은 일반 아동에 비해 연령이 증 가할수록 어휘력의 지체가 두드러지며(Jung \& Lee, 2008), 언어 사 용 경험의 부족과 관련된 배경 지식의 제한으로 인해 일반 아동보 다 낮은 어휘력을 보인다(Lee \& Choi, 2011). 또한 이들의 인지적 결 함은 언어의 구문론적, 화용론적 측면에 영향을 주어 새로운 어휘 를 습득하는 능력, 이미 알고 있는 어휘와 새로운 어휘를 구분하는 능력, 필요한 어휘를 회상하는 능력, 상황에 맞게 어휘를 사용하여 대화하는 능력 등에 영향을 미칠 수 있다(Son, 2003). 결론적으로, 학령기 아동의 어휘 습득의 어려움은 고차원적인 언어 처리와 읽 기 이해, 더 나아가 학업 성취를 저해하는 주요한 요인이 될 수 있기 때문에 이들의 어휘 습득에 관심을 갖고 연구하는 것은 매우 중요 하다 할수 있다.

경계선급 아동들의 의미 처리 특성을 알아본 선행 연구들을 보 면 다음과 같다. 경계선급 지능 아동들이 관용어를 이해할 때 문맥 을 활용하기는 하나 일반 아동들에 비해 덜 능숙하며, 관용어의 함 축적인 의미보다 문자적인 정보를 활용하여 해석하려는 경향을 보 인다고 하였고(Kim, 2015), 중의어 의미 처리를 알아본 연구에서는 그 의미를 처리하는 속도가 상대적으로 느렸으며, 특히 문맥 단서 가 주어진다 하더라도 우세의미보다 열세의미를 처리할 때 정확도 가 저조한 것으로 나타났다. 이같은 결과를 토대로 볼 때, 경계선급 지능 아동들은 문맥을 활용하여 의미를 습득하거나 처리하는 과 정에서 전반적으로 일반 아동들에 비해 저조함을 확인할 수 있다 (Yoo, 2016).

아동들이 어휘를 습득하기 위해서 크게 두 가지의 전략을 사용 한다. 먼저, 새로운 어휘가 사용된 문맥을 통해 그 의미를 추론하는 방법인데, 이때 문맥은 단어의 음운론적, 구문론적, 의미론적 규칙 과 같은 언어적 지식뿐만 아니라 문맥 속에서 단어가 어떻게 사용 되는지에 대한 모든 정보를 포함한다. 문맥을 통해 어휘를 습득하 는 것은, 어휘가 사용된 언어적 문맥 속에서 단서를 찾아내고, 그 단 서들과 자신의 어휘 지식, 경험 등과 같은 배경 지식을 활용하여 의 미를 추론하는 과정이 필요하며(Sternberg, 1987), 무엇보다 새로운 어휘의 적절한 쓰임에 대한 예시를 배움으로써 그 의미를 일반화하
여 사용할 가능성을 높여 준다는 이점이 있다(Amirian \& Momeni, 2012; Chen, Wang, \& Yang, 2014). 어휘를 습득하는 또 다른 방 법은 새로운 어휘의 정의를 통해 그 의미를 습득하는 방법으로, 어 휘의 정확한 의미와 동의어를 습득하는 데 용의하고, 이는 새로운 어휘의 의미를 직접적으로 개념화할 수 있다는 장점이 있기 때문에 특히 학령기 어휘력 확장에 중요한 역할을 하게 된다(Amirian \& Momeni, 2012). Pressley, Levin 그리고 McDaniel (1987)과 Biemiller (2006) 또한 단어의 의미를 분명하게 가르치는 것이 단어 목록 을 증가시키는 효과적인 방법이라고 논한 바 있으며, 학령전기 아 동들은 교과 과정 중에 고급 어휘를 접하게 되는 기회가 많기에 이 때 유용하게 사용하는 전략이 될 수 있다고 하였다.

선행 연구들을 고찰한 것을 바탕으로 본 연구에서는 학령기 경 계선급 지능 아동의 어휘 학습 특성을 밝히고자, 새로운 단어의 의 미를 추론할 수 있는 문맥을 제시하는 조건과 새로운 단어의 정의 를 제시하는 조건에서 경계선급 지능 아동들이 단어의 의미를 처 리하는 데 있어 일반 아동들과 차이가 있는지를 조사하였다. 또한 아동들이 오반응을 보였을 때 오류를 보이는 유형에 차이가 있는지 를 알아보았다. 문맥과 정의를 통한 어휘 습득 모두 유용한 전략이 지만 앞서 언급한 바와 같이 경계선급 지능 아동은 문맥 속에 포함 된 단서를 활용하고 자신이 가진 정보들을 새로운 정보와 통합하고 추론하는 데 어려움이 있기 때문에 정의를 통한 어휘 습득보다 문 맥을 통한 어휘 습득에 더 어려움을 보일 것으로 예측할 수 있다.

\section{연구 방법}

\section{연구대상}

본 연구는 경계선급 아동 10 명과 언어연령을 일치시킨 일반 아동 10 명을 대상으로 하였으며 구체적인 선정기준은 다음과 같다.

경계선 지능 아동의 선정기준은 (1) 한국-웩슬러 아동지능 검사 (Korean-Wechsler Intelligence Scale for Children-III, K-WISC-III; Kwak, Park, \& Kim, 2001) 결과 경계선 지능(IQ 70-84) 범주에 속 하고, (2) 수용·표현어휘력 검사(Receptive \& Expressive Vocabulary Test, REVT; Kim, Hong, Kim, Jang, \& Lee, 2009)에서 수용어 휘와 표현어휘가 8-9세 평균의 $\pm 1 \mathrm{SD}$ 범주에 속하면서, (3) 구문의 미이해력검사(Pae, Lim, Lee, \& Jang, 2004)에서 8-9세의 평균의 $\pm 1 \mathrm{SD}$ 범주에 속하고, (4) 읽기 성취 검사 및 읽기 인지처리능력 검 사(Test of Reading Achievement and Reading Cognitive Processes Ability, RA-RCP; Kim, Kim, Hwang, \& Yoo, 2014)의 ‘읽기 이해 성 취검사'에서 학년대비 $16 \%$ ile 이상으로 읽기 이해에 어려움이 없으 며, (5) 감각장애나 신경학적 손상을 수반하지 않는 아동으로 선정 
Table 1. Participants' characteristics

\begin{tabular}{lccc}
\hline & $\operatorname{BIF}(\mathrm{N}=10)$ & $\mathrm{NC}(\mathrm{N}=10)$ & $t$ \\
\hline Age (yr) & $9.46(.88)$ & $8.90(.63)$ & 1.618 \\
IO $^{\mathrm{a}}$ & $76.00(3.85)$ & $101.40(6.22)$ & $-10.971^{*}$ \\
Receptive vocabulary $^{\mathrm{b}}$ & $92.20(4.87)$ & $95.90(4.30)$ & -1.799 \\
Expressive vocabulary $^{\mathrm{b}}$ & $93.90(5.30)$ & $97.70(4.27)$ & -1.765 \\
Sentence comprehension $^{\mathrm{c}}$ & $49.60(2.36)$ & $51.60(2.36)$ & -1.890 \\
\hline
\end{tabular}

Values are presented as mean (SD).

$\mathrm{BIF}=$ borderline intellectual functioning; $\mathrm{NC}=$ normal children .

aKorean-Wechsler Intelligence Scale for Children-III (Kwak, Park, \& Kim, 2001), ' ${ }^{\text {Re- }}$ ceptive \& Expressive Vocabulary Test (Kim, Hong, Kim, Jang, \& Lee, 2009), ' Korean Sentence Comprehension Test (Pae, Lim, Lee, \& Jang, 2004). ${ }^{*} p<.001$.

하였다.

일반 아동의 선정기준은 (1) K-WISC-III 지능검사에서 정상(IQ 85 이상) 범주에 속하고, (2) REVT 검사에서 수용어휘와 표현어휘 수준이 8-9세 평균의 $\pm 1 \mathrm{SD}$ 범주에 속하면서, (3) 구문의미이해력 검사에서 구문이해가 8-9세 평균의 $\pm 1 \mathrm{SD}$ 범주에 속하고, (4) 읽 기 성취 검사 및 읽기 인지처리능력 검사의 '읽기 이해 성취검사'에 서 학년대비 $16 \% \mathrm{ile}$ 이상으로 읽기 이해에 어려움이 없으며, (5) 감 각장애나 신경학적 손상을 수반하지 않는 아동으로 선정하였다.

경계선 지능 아동 집단과 일반 아동 집단의 선정 기준에서 있어 유의한 차이가 있는지 살펴보기 위해 독립표본 $t$-검정을 실시하였 다. 그 결과 지능에서 집단 간 유의한 차이를 보인 것 $(t=-10.971$, $p<.001)$ 외에, 생활연령, REVT 수용어휘 및 표현어휘, 구문의미이 해력검사에서는 유의한 차이가 나타나지 않았다. 두 집단의 기본 정보 및 $t$-검정 결과는 Table 1 과 같다.

\section{실험 도구 제작}

본 과제는 새로운 단어의 의미를 처리하는 과제로, 아동이 비단 어가 포함된 목표 문장을 읽으면서 문장 내 포함된 단서들을 활용 하여 비단어의 의미를 확인한 후, 같은 비단어가 포함된 3개의 보기 문장 중에서 목표 문장에서 사용된 비단어의 의미와 같은 의미로 사용된 문장을 고르는 방식이다. 이때 목표 문장은 정의제시 조건 과 문맥제시 조건으로 구분되며, 각 조건은 12 개의 문항으로 구성 되었다. 정의제시 조건은 목표 문장이 비단어의 의미를 직접적으로 설명하는 방식으로 진술되는 반면, 문맥제시 조건은 목표 문장이 비단어가 실제로 그 의미에 맞게 사용되는 예시 형태로 제시된다.

이 같은 실험 문항을 제작하기 위하여 우선적으로 비단어와 비 단어의 의미를 선정하였고, 그 비단어가 포함된 각 조건의 목표 문 장을 제작하였으며, 마지막으로 각각의 목표 문장에 대한 3 개의 보 기 문장을 제작하였다. 그 제작 과정은 다음과 같다.
실험에 사용되는 비단어는 복잡한 음절구조를 제외하고, 실제 단어에서 빈번하게 나타나는 CVCV, CVCVC, CVCCV 구조의 2 음절로 총 24 개를 선정하였다. 비단어의 개별 의미는 일상생활에 존재하는 구체적인 명사이기는 하나, 하나의 대상으로 국한되기 보 다는 같은 속성을 갖는 여러 개의 대상으로 추론될 수 있도록 하였 다. 또한 비단어를 제외하고 목표 문장과 보기 문장에서 사용된 모 든 단어들은 아동이 이미 알고 있는 단어들이어야 하기 때문에 Kim (2003)의 ‘등급별 국어 교육용 어휘’에서 1 등급, 2 등급에 해당하는 단어이면서 초등학교 교과서에 포함된 단어들만을 사용하였다. 실 험에 사용된 목표 문장과 보기 문장은 문장의 통사적 길이와 복잡 성을 통제하기 위해 4-6어절로 제한하여 제작하였다.

또한, 각 조건의 목표 문장에는 아동의 비단어 의미를 추론할 수 있도록 하는 세 가지의 단서를 포함하도록 하였다. 예를 들면, 정의 제시 조건의 목표 문장인 “뽀디는 봄에 피는 꽃입니다”에서 “뽀디' 라는 비단어의 의미를 추론할 수 있는 세 가지 단서로 '봄, '피다', '꽃’을 사용하였으며, 문맥제시 조건의 목표 문장인 “봄에 뽀디가 피면 향기가 납니다”에서는 세 가지 단서로 '봄' '피다', ‘향기’를 사 용하였다. 이때 비단어 추론을 위해 사용되는 단서들을 두 제시 조 건에서 최대한 동일하게 하고자 하였는데, 대응되는 두 제시 조건 의 목표 문장에서 세 가지의 단서 중 두 가지(예: '봄'과 '피다')는 두 제시 조건에서 동일하게 사용되었고, 각 조건에 알맞게 자연스러운 문장을 만들고자 한 가지의 단서는 두 조건에서 다르게 사용되었 다. 이때 두 조건에서 달리 사용된 하나의 단서로 정의제시 조건에 서는 상위범주어(예: '꽃')를, 문맥제시 조건에서는 비단어의 의미 를 추론할 수 있는 추가적인 단서(예: '향기')를 제시하였다. 이 같은 조건은 모든 문항에서 동일하게 적용하였다.

더불어, 각각의 목표 문장마다 3 개의 보기 문장을 제작하였는 데, 보기에는 목표 문장과 같은 의미로 사용된 비단어가 포함된 문 장(이하 정답 문장), 목표 문장에서 사용한 비단어의 의미는 아니 지만 관련이 있는 의미로 사용된 문장(이하 관련 있는 문장), 마지 막은 목표 문장에서 사용한 비단어의 의미와 전혀 관련이 없는 의 미로 사용된 문장(이하 관련 없는 문장)으로 구성된다. 보기 문장 중 정답 문장은 목표 문장에서 사용된 세 가지 단서가 중복적으로 사용되지 않으며, 비단어의 의미와 관련된 두 가지의 다른 의미 단 서가 포함되도록 하였다. 예를 들면 ‘화분에 있던 뽀디가 시들었습 니다'로 두 조건의 목표 문장에 사용된 단서인 '봄, 피다, 꽃, 향기'와 중복되지 않는 '화분, 시들다'라는 두 가지 단서를 포함하고 있다. 보기 문장 중 관련 있는 문장에 사용된 비단어의 의미는 목표 문장 에서 사용된 비단어의 의미와 같은 범주에 속하지만, 기능이 유사 하지 않은 의미로 선정하였다. 예를 들어 '뽀디에 열린 사과를 땄습 
니다.' 문장에서 ‘뽀디’의 의미는 '나무’로 목표 문장의 비단어의 의 미인 '꽃'과 같은 범주에 속하여 연관이 있는 의미가 된다. 또한, 선 택 문장 중 관련 없는 문장에 사용된 비단어의 의미는 목표 문장에 사용된 비단어 의미와는 다른 범주에 속하며, 기능 또한 유사하지 않은 의미로 선정하였다. 예를 들어 '날짜를 보려고 뽀디를 넘겼습 니다.'에서 '뽀디'는 '달력'을 의미하여 목표 문장에 사용된 비단어 의 의미인 '꽃'과는 같은 범주에도 속하지 않고, 기능 또한 확연히 다른 것이다. 이와 같은 과제 제작 과정을 거쳐 제작된 정의제시 조 건과 문맥제시 조건의 예시 문항은 Appendix 1과 같다.

과제 제작 기준에 따라 1 차적으로 과제를 제작한 후, 과제가 적 절한지를 알아보고자 경계선급 지능 아동 3명과 일반 아동 3 명을 대상으로 예비실험을 실시하였고 결과에 따라 문장의 길이, 친숙 성, 난이도를 조정하였다. 이후 2 급 언어재활사 자격증을 소지하고, 3 년 이상의 임상경력이 있는 언어재활사 5 명에게 선정된 비단어의 형태와 의미가 적절한지, 목표 문장과 선택 문장이 기준에 맞게 제 작되었는지를 알아보고자 타당도 검사를 실시하였다. 그 결과 대 부분 타당한 것으로 나타났으나 비단어 중 실제 단어와 지나치게 비슷하다고 보고된 2개의 비단어를 수정하였고, 목표 문장과 보기 문장에서 부적절하다고 보고된 문장은 부분적으로 수정.보완하여 최종 과제를 완성하였다.

\section{연구 절차}

각 조건 당 24 문항씩 총 48 문항을 제작하였으나 두 조건에서 같 은 의미의 비단어를 사용하였기 때문에 아동에게 동일한 의미의 비단어가 포함된 문장이 중복되어 제시되는 것을 피하기 위하여 각 조건을 12 문항씩 $\mathrm{A}, \mathrm{B}$ 세트로 나누어, 각 집단 아동들의 반은 정 의제시 조건 $\mathrm{A}$ 세트와 맥락제시 조건 $\mathrm{B}$ 세트를, 나머지 아동들은 정 의제시 조건 B세트와 맥락제시 조건 $\mathrm{A}$ 세트를 수행하도록 하였다. 이때 각 세트 내의 문항들은 무작위로 배치하여 순서 효과를 배제 하였다.

본 실험은 조용한 교실이나 치료실, 가정에서 아동과 개별적으 로 실시하였다. 지능검사와 언어검사(REVT, 구문의미이해력검사), 읽기 이해 검사(RA-RCP)를 먼저 실시하였으며, 5 분간 휴식 후 비 단어 의미 추론 과제를 실시하였다. 본 과제 실시에 앞서 연습 문항 을 실시함으로써 아동들이 과제에 익숙해질 수 있도록 하였고, 과 제를 실시할 때 아동들에게 목표 문장과 선택 문장을 소리 내어 읽 도록요구한 후 답을 고르도록 하였다.

\section{자료분석 및 처리}

정의제시 조건과 문맥제시 조건에서 정반응 1 점, 오반응 0 점으로
처리하여 각 조건 당 총점은 12 점이었다. 각각의 아동에 대한 정반 응 수를 계산하고, 오반응에 대해서는 오류 유형을 분석하였다.

경계선 지능 아동 집단과 일반 아동 집단 간 정의제시 조건과 문 맥제시 조건에 따른 단어의미 추론에 차이가 있는지를 알아보고 자 집단(2) $\times$ 조건(2)의 이원분산분석(two-way ANOVA)을 실시하 였다. 또한, 단어의미 추론과제에서 나타난 오류유형을 알아보기 위해 기술통계를 실시하였다. 자료의 통계 처리는 SPSS ver. 18.0을 사용하였다.

\section{연구결과}

\section{경계선급 지능 아동과 일반 아동의 단어의미 추론 비교}

기술통계 결과를 살펴보면, 경계선급 지능 아동들의 경우 비단 어의 의미를 추론하는 데 있어 일반 아동들에 비해 저조한 수행을 보였으며, 일반 아동들의 경우 제시 조건과 상관없이 그 수행이 유 사한 데 반해 경계선급 지능 아동들은 정의제시 조건에서보다 문 맥제시 조건에서 저조한 수행을 보이는 것으로 나타났다. 경계선 지능 아동과 일반 아동의 두 조건에 따른 비단어 의미 추론에 대한 기술통계 결과는 Table 2와같다.

경계선 지능 아동 집단과 일반 아동 집단 간 제시 조건에 따라 비 단어의 의미 처리에 차이가 있는지를 알아보고자 이원분산분석 (mixed two-way ANOVA)을 실시하였다. 그 결과 집단 간 주효과 가 유의미하였고 $\left(F_{(1,18)}=34.961, p<.001\right)$, 제시 조건 간 주효과가 유의미하였으며 $\left(F_{(1,18)}=5.184, p<.05\right)$, 제시 조건 $\times$ 집단의 상호작 용 효과 역시 유의미한 것으로 나타났다 $\left(F_{(1,18)}=7.056, p<.05\right)$. 이 는 경계선 지능 아동과 일반 아동이 비단어 의미 추론 수행에 차이 가 있음을 보여주고, 비단어의 의미를 추론함에 있어 목표 문장의 제시 조건이 두 집단에 다르게 영향을 미친 것으로 해석할 수 있다. 이원분산분석에 대한 결과는 Table 3 과 같다.

집단과 제시 조건의 상호작용을 설명하기 위하여 각 집단별로 정 의제시 조건과 문맥제시 조건에 따른 $t$-검정을 실시한 결과, 경계선 지능 아동은 정의제시 조건과 문맥제시 조건 간에 유의한 차이 $(t=2.751, p<.05)$ 가 나타났으나, 일반 아동은 두 조건 간에 유의한 차이가 나타나지 않았다. 이를 통해, 일반 아동은 두 조건에서 단어

Table 2. Descriptive statistics of word meaning processing task by groups

\begin{tabular}{lll}
\hline & $\mathrm{BIF}(\mathrm{N}=10)$ & $\mathrm{NC}(\mathrm{N}=10)$ \\
\hline Definition presentation condition & $8.50(1.43)$ & $10.70(.94)$ \\
Context presentation condition & $7.20(1.47)$ & $10.80(1.03)$ \\
\hline
\end{tabular}

Values are presented as mean (SD).

$\mathrm{BIF}=$ borderline intellectual functioning; $\mathrm{NC}=$ normal children. 
Eunji Kim, et al. • Inference Word Meaning of Children with Borderline Intelligence

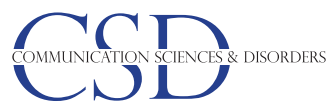

Table 3. Result of two-way ANOVA by group and condition

\begin{tabular}{lrrrrr}
\hline Source & $\begin{array}{c}\text { Type III sum } \\
\text { of squares }\end{array}$ & df & $\begin{array}{r}\text { Mean } \\
\text { square }\end{array}$ & $F$ & $p$-value \\
\hline $\begin{array}{l}\text { Between group } \\
\quad \text { Group }\end{array}$ & 84.100 & 1 & 84.100 & 34.961 & $.000^{* * * *}$ \\
$\quad$ Error & 43.300 & 18 & 2.406 & & \\
$\quad \begin{array}{l}\text { Within group } \\
\quad \text { Condition }\end{array}$ & 3.600 & 1 & 3.600 & 5.184 & $.035^{*}$ \\
$\quad$ Condition×Group & 4.900 & 1 & 4.900 & 7.056 & $.016^{*}$ \\
$\quad$ Error & 12.500 & 18 & .694 & & \\
\hline
\end{tabular}

${ }^{*} p<.05,{ }^{* * *} p<.001$.

의미 추론 수행에 차이가 없었지만, 경계선 지능 아동은 두 조건 중 문맥제시 조건에서 단어의미를 추론하는 데 더 어려움을 보인 것 을 알 수 있다.

\section{경계선 지능 아동과 일반 아동의 단어의미 추론 오류 유형}

경계선 지능 아동과 일반 아동의 단어의미 추론에 대한 오류 유 형별 빈도 및 백분율은 Table 4 와 같다.

오류 빈도 분석 결과 경계선 지능 아동은 단어의미 추론 과제에 서 평균 $8.30(\mathrm{SD}=2.49)$ 개의 오류를 보여 일반 아동의 평균 2.50 $(\mathrm{SD}=1.84)$ 개와 비교하여 오반응 빈도가 더 높았다. 두 집단의 오 류 유형을 살펴보면, 경계선 지능 아동은 전체 오류 중 관련 있는 문장을 선택한 오류가 평균 $5.80(\mathrm{SD}=1.68)$ 개로 백분율이 $69.88 \%$ 였으며, 일반 아동은 $2.30(\mathrm{SD}=1.63)$ 개로 전체 오류 중 $92.00 \%$ 로 나타났다. 전체 오류 중 관련 없는 문장을 선택한 오류가 경계선 지 능 아동은 평균 $2.50(\mathrm{SD}=2.12)$ 개로 백분율이 $30.12 \%$ 였으며, 일반 아동은 $0.2(\mathrm{SD}=0.63)$ 개로 백분율이 $8.00 \%$ 로 나타났다.

\section{논의 및 결론}

본 연구는 아동들에게(경계선급 지능 아동, 일반 아동) 비단어의 의미를 개념화할 수 있도록 정의제시 조건과 문맥제시 조건의 문장 을 제시하였고 비단어의 의미를 개념화한 후 보기 문장에서 비단 어가 같은 의미로 사용된 문장을 고르도록 함으로써 경계선급 지 능 아동들의 단어 습득 특성을 밝히고자 하였다. 또한 아동들이 오 류를 보인 문장에 대하여 그 오답 유형을 분석함으로써 경계선급 지능 아동들의 수행이 일반 아동들과 다른 양상을 보이는지를 조 사하였다. 이 같은 연구의 결과를 바탕으로 다음과 같이 논의하고 자 한다.

첫째, 경계선급 지능 아동이 단어의미 처리 과제에서 언어연령을 일치시킨 일반 아동보다 통계적으로 유의하게 낮은 점수를 얻어 새 로운 단어의 의미를 추론 및 개념화하는 데 있어 일반 아동들에 비
Table 4. Frequency and percentage of error type by groups

\begin{tabular}{lccccc}
\hline \multirow{2}{*}{ Error type } & \multicolumn{2}{c}{$\mathrm{BIF}(\mathrm{N}=10)$} & & \multicolumn{2}{c}{$\mathrm{NC}(\mathrm{N}=10)$} \\
\cline { 2 - 3 } \cline { 5 - 6 } & $\mathrm{M}(\mathrm{SD})$ & $\begin{array}{c}\text { Percentage } \\
(\%)\end{array}$ & & $\mathrm{M}(\mathrm{SD})$ & $\begin{array}{c}\text { Percentage } \\
(\%)\end{array}$ \\
\hline Relevant sentence & $5.80(1.68)$ & 69.88 & & $2.30(1.63)$ & 92.00 \\
Irrelevant sentence & $2.50(2.12)$ & 30.12 & & $.20(.63)$ & 8.00 \\
Total & $8.30(2.49)$ & 100 & & $2.50(1.84)$ & 100 \\
\hline
\end{tabular}

$\mathrm{BIF}=$ borderline intellectual functioning; $\mathrm{NC}=$ normal children .

해 저조한 수행을 보였음을 알 수 있다. 본 연구의 과제는 목표 문장 을 읽으면서 단어의 의미를 추론 및 개념화하고, 보기 문장들을 읽 으면서 목표 문장에서 쓰인 비단어의 의미와 같은 의미로 사용된 문장을 선택하게 되는데 이 과정에서 복잡한 인지적인 처리가 요구 된다. 이 같은 과정에서 경계선급 지능 아동들은 두드러진 언어 문 제를 동반하지 않았음에도 인지적인 처리의 비효율성으로 인해 일 반 아동들보다 더 많은 오류를 보인 것으로 해석할 수 있다. 이는 선 행 연구들에서 경계선급 지능 아동들이 언어적 문맥을 이해하고 정보를 통합하고 일반화하는 데 어려움을 보인다고 보고한 것과 일 치하는 결과이다(Jensen, 1998; Lee \& Choi, 2011; Masi, Marcheschi, \& Pfanner, 1998; Verguts \& De Boeck, 2001).

둘째, 일반 아동의 경우 목표 문장에서 정의를 제시하는 조건과 문맥을 제시하는 조건에 따라 크게 영향을 받지 않고 일관된 수행 을 보인 반면 경계선급 지능 아동들의 경우 목표 문장의 비단어 제 시 조건에 따라 단어의 의미 추론에 유의한 차이를 보였다. 이같은 결과로 보아 일반 아동들과 달리 경계선급 지능 아동들이 정의제 시 조건보다 문맥제시 조건에서 단어의미를 추론하는 데 더 어려 움을 보인다는 것을 알 수 있다. 문맥제시 조건은 그 의미를 추론할 수 있는 단서를 포함하고 있어 아동들이 이를 활용하여 의미를 추 론하고 개념화해야 하는 반면 정의하기는 “ 은 이다”의 구문을 사용하여 비단어의 의미를 구체적으로 설명하고 있기 때문에 있는 대로의 의미를 기억하여 문항을 처리하면 된다. 결과적으로, 각각 의 조건에서 요구되는 비단어의 의미 처리 과정의 차이로 인해 경 계선급 지능 아동들의 경우 두 조건에서 수행 차이를 보인 것으로 해석할 수 있다. Amirian과 Momeni (2012)에 의하면 문맥을 통해 단어를 습득하는 것이 단어 지식뿐만 아니라 문맥 속에서 단어가 사용되는 정보를 습득할 수 있으며, 하나의 단어를 여러 문맥에서 접함으로써 그 의미를 일반화할 수 있다고 하였다. 또한 학령기에 접어들면 많은 단어들에 수시로 노출이 되기 때문에 그 단어들의 정의를 찾아 의미를 습득하는 데에는 한계가 있어 문맥을 통한 단 어의 의미 습득 전략은 학령기 아동들의 어휘 확장에 대단히 중요 한 기술이라 할 수 있다(Amirian \& Momeni, 2012; Chen et al., 2014; 
Sternberg, 1987). 그러나 본 연구의 결과에서처럼 경계선급 지능 아동들은 문맥을 활용하여 새로운 단어의 의미를 추론하는 데 상 대적으로 어려움을 보이기 때문에 이것이 연령이 증가할수록 이들 의 어휘력 지체가 두드러지는 원인으로 작용할 수 있겠다(Jung \& Lee, 2008). 이같은 결과는 문맥을 활용한 의미 추론이 요구되는 중 의어와 관용어의 의미를 이해할 때 저조한 수행을 보였다는 선행 연구의 결과들과 맥을 같이 한다(Kim, 2015; Yoo, 2016)

셋째, 단어의미 처리 과제에서 오류에 대하여 그 유형을 분석하 였는데 일반 아동과 경계선급 지능 아동 모두 목표 문장에서 사용 된 비단어의 의미와 관련이 있는 오답을 고르는 경향을 보였다. 그 러나 눈에 띄는 점은 일반 아동들의 경우 목표 문장에서 사용된 비 단어와 전혀 관련이 없는 오답을 고르는 확률이 매우 낮은 데 비해 경계선 지능 아동은 관련 없는 문장을 선택한 비율이 일반 아동에 비해 높게 나타났다는 점이다. 일반적으로 새로운 단어에 노출되었 을 때 단번에 그 단어의 의미를 완전하게 습득하지 못한다 할지라 도 그 단어의 일부의 속성들을 습득하고 이후 반복적인 노출을 통 해 점차적으로 어휘 지식을 확장해 나감으로써 단어의 의미를 개 념화하게 된다(Amirian \& Momeni, 2012). 일반 아동들은 오답을 고르더라도 비단어의 의미와 관련이 있는 문장을 선택함으로써 새 로운 단어의 일부 의미를 습득할 가능성이 높을 것으로 예측되나 경계선급 아동들은 이조차도 실패하는 확률이 높아 관련이 없는 보기 문장을 고르는 빈도가 높았던 것으로 짐작할 수 있다.

위의 연구 결과를 종합해보면, 경계선 지능 아동은 문맥을 활용 하여 단어의 의미를 습득하는 데 어려움이 있고, 이같은 어려움은 학령기에 접어들면서 읽기 이해 및 학습에 부정적인 영향을 미칠 수 있다. 따라서 경계선급 지능 아동들의 어휘를 중재할 때 정의하 기 방식을 활용하는 것이 유리할 수는 있겠으나 일상 생활에서 우 연적으로 새로운 단어를 접할 때마다 사용할 수 있는 전략이 아니 라는 단점을 감안했을 때 궁극적으로는 이들이 문맥을 활용하여 어휘의 의미를 습득할 수 있도록 중재하는 것이 주요할 것으로 생 각된다.

본 연구는 어휘와 읽기 이해에 어려움이 보이지 않는 학령기 경 계선급 지능 아동을 대상으로 하여 이들의 의미 습득의 어려움을 밝혔다는 점에서 의미가 있다. 경계선급 지능 아동들의 경우 다른 장애와 달리 학령기에 접어 들어서도 이들의 문제가 확인 되지 않 아 적절한 중재 시기를 놓칠 수 있기에 후속 연구들을 통해 이들의 언어 및 학습 특성을 자세히 밝히는 것은 임상적으로 의의가 있을 것이다.

\section{REFERENCES}

American Psychiatric Association (2000). Diagnostic and Statistical Manual of Mental Disorders fourth edition text revision (DSM-IV-TR). Washington, DC: Author

Amirian, S. M. R., \& Momeni, S. (2012). Definition-based versus contextualized vocabulary learning. Theory and Practice in Language Studies, 2, 23022307.

Biemiller, A. (2006). Vocabulary development and instruction: a prerequisite for school learning. In D. K. Dikinson \& S. B. Neuman (Eds.), Handbook of early literacy research (2nd ed., pp. 41-51). New York: Guilford Press.

Cain, K., Oakhill, J., \& Lemmon, K. (2004). Individual differences in the inference of word meanings from context: the influence of reading comprehension, vocabulary knowledge, and memory capacity. Journal of Educational Psychology, 96, 671-681.

Chen, S., Wang, L., \& Yang, Y. (2014). Acquiring concepts and features of novel words by two types of learning: direct mapping and inference. Neuropsychologia, 56, 204-218.

Cooter, K. S., \& Cooter, R. B. (2004). One size doesn't fit all: slow learners in the reading classroom. The Reading Teacher, 57, 680-685.

Cunningham, A. E., \& Stanovich, K. E. (1998). What reading does for the mind? American Educator, 22, 8-15.

Dunham, M. D., Schrader, M. P., \& Dunham, K. S. (2000). Vocational rehabilitation outcomes of adults with co-morbid borderline IQ and specific learning disabilities. Journal of Rehabilitation, 66, 31-36.

Jensen, A. R. (1998). The g factor: the science of mental ability. Westport, CT: Praeger.

Jung, H. J., \& Lee, J. Y. (2005). The analysis on the cognitive, behavior characteristics of the borderline intellectual functioning children. Korean Journal of Child Welfare, 3, 109-124.

Jung, H. J., \& Lee, J. Y. (2008). The characteristics of borderline intellectual functioning children. Korean Journal of Special Education, 42, 43-66.

Kim, A. H., \& Hwang, M. (2008). Prediction of reading skills in upper elementary students. Korean Journal of Communication Disorders, 13, 1-25.

Kim, A. H., Kim, U. J., Hwang, M., \& Yoo, H. S. (2014). Test of Reading Achievement and Reading Cognitive Processes (RA-RCP). Seoul: Hakjisa.

Kim, A. H., Yoo, H. S., Hwang, M., Kim, U. J., \& Koh, S. R. (2010). Prediction of reading comprehension in elementary school students. Korean Journal of Communication Disorders, 15, 357-380.

Kim, K. H. (2003). Grade level vocabulary list. Seoul: Pagijung. 
Eunji Kim, et al. • Inference Word Meaning of Children with Borderline Intelligence

Kim, S. J. (2015). Comprehension of idioms in school-aged children with borderline intelligence (Master's thesis). Dankook University, Yongin, Korea.

Kim, Y. T., Hong, G. H., Kim, K. H., Jang, H. S., \& Lee, J. Y. (2009). Receptive \& expressive vocabulary test (REVT). Seoul: Seoul Community Rehabilitation Center.

Kurdek, L. A., \& Sinclair, R. J. (2001). Predicting reading and mathematics achievement in fourth-grade children from kindergarten readiness scores. Journal of Educational Psychology, 93, 451-455.

Kwak, K. C., Park, H. W., \& Kim, C. T. (2001). Korean Wechsler Intelligence Scale for Children-III (K-WISC-III). Seoul: Seoul Special Education Publishing.

Lee, H. M., \& Choi, Y. L. (2011). Comparison of fast-mapping according to semantic cues of normal children and children with mental retardation. Journal of Speech-Language \& Hearing Disorders, 20, 87-102.

Lee, J. S. (1997). Principles and methods of language teaching: the focus of process. Seoul: Pagijung.

Lim, J., \& Hwang, M. (2006). Grammaticality judgement and error correction by children with developmental language impairments. Speech Sciences, $13,59-72$.

Masi, G., Marcheschi, M., \& Pfanner, P. (1998). Adolescents with borderline intellectual functioning: psychopathological risk. Adolescence, 33, 415-424.

Nagy, W. E., \& Herman, P. A. (1987). Breadth and depth of vocabulary knowledge: implications for acquisition and instruction. In M. G. McKeown \& M. E. Curtis (Eds.), The nature of vocabulary acquisition (pp. 19-35). Hillsdale, NJ: Lawrence Erlbaum Associates.
Nagy, W. E., Herman, P. A., \& Anderson, R. C. (1985). Learning words from context. Reading Research Quarterly, 20, 233-253.

Pae, S., Lim, S. S., Lee, J. H., \& Jang, H. S. (2004). Korean Oral Syntax Expression Comprehension Test (KOSECT). Seoul: Seoul Community Rehabilitation Center.

Pressley, M., Levin, J. R., \& McDaniel, M. A. (1987). Remembering versus inferring what a word means: mnemonic and contextual approaches. In M. G. McKeown \& M. E. Curtis (Eds.), The nature of vocabulary acquisition (pp. 107-127). Hillsdale, NJ: Lawrence Erlbaum Associates.

Singh, V. P. (2004). Education of the slow learners. New Delhi: Sarup \& Sons. Son, M. S. (2003). A study on the speech language ability of children with mental retardation by multi-fairy tales teaching through Internet (Master's thesis). Dankook University, Yongin, Korea.

Sternberg, R. J. (1987). Most vocabulary is learned from context. In M. G. McKeown \& M. E. Curtis (Eds.), The nature of vocabulary acquisition (pp. 89-105). Hillsdale, NJ: Lawrence Erlbaum Associates.

Verguts, T., \& De Boeck, P. (2001). On the correlation between working memory capacity and performance on intelligence tests. Learning and Individual Differences, 13, 37-55.

Yoo, S. M. (2016). Comprehension of lexical ambiguity in school-aged children with borderline intelligence (Master's thesis). Dankook University, Yongin, Korea.

Yu, G., Jeong, E. H., \& Kim, L. H. (2007). Characteristics of language in the school-aged children with borderline intelligence. Journal of Special Children Education, 9, 193-209. 
Appendix 1. 정의제시 조건과 문맥제시 조건의 예

(1) 화분에 있던 뽀디가 시들었습니다. (정답 문장)

(2) 뽀디에 열린 사과를 땄습니다. (관련 문장)

(3) 날짜를 보려고 뽀디를 넘겼습니다. (비관련 문장)

문맥제시 조건 봄에 뽀디가 피면 향기가 납니다.

(1) 화분에 있던 뽀디가 시들었습니다. (정답 문장)

(2) 뽀디에 열린 사과를 땄습니다. (관련 문장)

(3) 날짜를 보려고 뽀디를 넘겼습니다. (비관련 문장) 


\title{
국문초록
}

\author{
경계선급 지능 아동의 정의제시 조건과 문맥제시 조건에 따른 비단어 의미 추론 특성 \\ 김은지 ${ }^{1}$ 황민아 $\cdot$ 고선희 ${ }^{1}$ \\ 1단국대학교 일반대학원 언어병리학과, ${ }^{2}$ 단국대학교 특수교육과
}

배경 및 목적: 본 연구에서는 정의제시 조건과 문맥제시 조건에서 비단어의 의미를 처리하는 데 있어 경계선급 지능 아동들이 일반 아 동과 차이가 있는지를 알아보고자 하였다. 방법: 8-9세의 경계선급 지능 아동과 일반 아동 각각 10 명씩을 대상으로 하였으며, 아동들에 게 비단어가 포함된 목표 문장을 읽고 3 개의 보기 중에서 그 비단어의 의미와 같은 의미로 사용된 비단어가 포함된 문장을 고르도록 하였다. 이때 목표 문장은 비단어의 정의를 제시하는 조건과 비단어의 의미를 추론할 수 있는 문맥을 제시하는 조건으로 나뉘었다. 결 과: 경계선급 지능 아동들은 비단어 의미를 처리하는 데 있어 두 조건 모두에서 일반 아동들에 비해 유의미하게 낮은 수행을 보였으며, 일반 아동들은 조건과 상관없이 고른 수행을 보인 반면 경계선급 지능 아동들은 정의제시 조건에서보다 문맥제시 조건에서 유의미하 게 낮은 수행을 보였다. 또한, 오류 유형을 분석한 결과, 경계선급 지능 아동들은 일반 아동들에 비해 목표 문장에서 사용된 비단어의 의미와 관련이 없는 오답을 고르는 비율이 높았다. 논의 및 결론: 경계선 지능 아동들은 전반적으로 새로운 단어의 의미를 습득하는 데 어려움을 보이며, 특히 문맥을 활용하여 단어의 의미를 추론하는 데는 더 많은 어려움이 있는 만큼 이에 대한 적절한 중재가 이뤄져 야할 것이다.

핵심어: 경계선 지능 아동, 단어 의미 추론, 정의 제시, 문맥 제시

\section{참고문헌}

곽금주, 박혜원, 김청택(2001). 한국 웩슬러 아동 지능검사-III (Korean Wechsler Intelligence Scale for Children-III). 서울: 도서출판 특수교육.

김광해(2003). 등급별 국어교육용어휘. 서울: 도서출판 박이정.

김수진(2015). 학령기 경계선급 지능 아동의 관용어 이해능력. 단국대학교대학원 석사학위논문.

김애화, 김의정, 황민아, 유현실(2014). 읽기 성취 및 읽기 인지처리 검사(RA-RCP). 서울: 학지사 심리검사연구소.

김애화, 유현실, 황민아, 김의정, 고성룡(2010). 초등학생의 읽기이해 능력 예측변인에 관한 연구. 언어청각장애연구, 15, 357-380.

김애화, 황민아(2008). 초등학교 고학년의 읽기능력에 영향을 미치는 읽기관련변인에 관한 연구. 언어청각장애연구, 13, 1-25.

김영태, 홍경훈, 김경희, 장혜성, 이주연(2009). 수용·표현어휘력검사(REVT). 서울: 서울장애인종합복지관.

배소영, 임선숙, 이지희, 장혜성(2004). 구문의미이해력점사. 서울: 서울장애인종합복지관.

손명숙(2003). 인터넷을 활용한 멀티동화지도가 정신지체아의 언어표현력에 미치는 효과. 단국대학교대학원 석사학위논문.

유경, 정은희, 김락형(2007). 학령기 경계선지능 아동의 언어특성 연구. 특수아동교육연구, 9, 193-209.

유승미(2016). 학령기 경계선급 지능 아동의 어휘적 중의성 이해. 단국대학교대학원 석사학위논문.

이재승(1997). 국어교육의 원리와 방법: 과정 중심의 국어교육. 서울: 박이정.

이효미, 최예린(2011). 일반 아동과 지적장애 아동의 의미단서에 따른 빠른 연결 능력 비교. 언어치료연구, 20, 87-102.

임종아, 황민아(2006). 경계선지능 언어발달장애아동과 일반아동의 문법성 판단 및 오류수정. 음성과학, 13, 59-72.

정희정, 이재연(2005). 경계선지능 아동의 인지적, 행동적 특성. 아동복지연구, 3, 109-124.

정희정, 이재연(2008). 경계선 지적 기능 아동의 특성. 특수교육학연구, 42, 43-66. 